\title{
Digital Solutions to the Problems of Chinese Students in St. Petersburg Multilingual Space
}

\author{
https://doi.org/10.3991/ijet.v16i22.25233 \\ Daria Bylieva $^{1}(\sqrt[\varpi]{ })$, Victor Krasnoshchekov ${ }^{1}$, Victoria Lobatyuk ${ }^{1}$, Anna Rubtsova ${ }^{1}$, \\ Li Wang ${ }^{2}$ \\ ${ }^{1}$ Peter the Great St. Petersburg Polytechnic University, St. Petersburg, Russia \\ ${ }^{2}$ Jiangsu Normal University, Jiangsu, China \\ bylieva_dsespbstu.ru
}

\begin{abstract}
Multilingual space is considered as one of the most important parts of the cultural environment that becomes a challenge for international students. The research examined the multilingual space of St. Petersburg from the perspective of young people from China. Included observation, short interviews and analysis of Chinese freshmen essays serve as a source for the formation of a database of multilingual objects of everyday life of Chinese students and reveal language problems as the main challenges in the city multilingual space for a foreigner. The authors proposed an approach dividing the multilingual space of the city into space of communication and the "physical space of the language", existing vertically in three levels (city, university and personal areas). Expansion of the multilingual space at all levels due to the digital environment can significantly improve the language adaptation of students Although a coherent digital environment that provides the Chinese dimension to a multilingual environment does not yet exist. However, such elements as specially developed electronic guides and dictionaries, maps, augmented reality applications, communication platforms in social networks, etc. contribute to its future creation.
\end{abstract}

Keywords - multilingual space, the digital space of multilingualism, St. Petersburg, international student, multilingualism

\section{$1 \quad$ Introduction}

Academic mobility, international educational programms, service learning, noncredit internships, work placements have become part of the global world, and even the Covid19 pandemic could not fully stop the movement of international students who continue to enter universities and study far from their homeland, although sometimes online.

The formation of intercultural competence often plays an important role in research on international students. The versatility, complexity of the formation and assessment of this competence have been demonstrated in numerous studies [1-4]. Researchers point out that intercultural competence is not an automatic result of living in a different cultural environment $[5,6]$. 
According to the theory of socio-psychological adaptation, formed in the 1970s1990 s, the rapid mastery of the language of the country by temporary residence was considered as one of the main conditions for the successful adaptation, supported by intensive communication with representatives of other cultures [7]. Some authors studying small cultural communities in a foreign language environment continue to follow the plan of background adaptation created in the 20th century [8]. However, due to globalization, world migration flows have increased, that has led to the emergence of big and homogeneous linguistic communities, within which communication is carried out in the native language. To a large extent, this also affected universities, mainly due to the increase in the number of Chinese students. According to the recent studies adaptation of Chinese students turns out to be effective if representatives of Chinese culture are involved in this process [9].

Many authors analyze the process of formation of intercultural identity or "global citizenship", indicating initial stress from exposure to a new cultural environment [1014]. Cultural environment is an extremely complex multidimensional sociocultural phenomenon. At the same time, it seems possible to single out the linguistic component, which plays a very important role in the formation of intercultural identity. It means that foreign language learning is not the only key to success $[15,16]$. Multilingual space is a linguistic environment where international student is involved in a foreign country. Development of multilingual component and its analysis may contribute to identification of key challenges and the formation of appropriate educational policy.

Blommaert, Collins, \& Slembrouck prove that space must be seen as constitutive and agentive in organizing patterns of multilingualism [17]. The authors show that multilingualism is not individuals who have certain linguistic competences, but the space, as structured determination and interactional emergence, enables and disables them to deploy. Tittley points out that a man does not so much construct material culture or language, but is rather constructed through them [18]. Wei (2011) also indicates transformative power of the space creating with the help of multilingual practices [19]. The most obvious way to study multilingual space from a student perspective is analysis of the classes and policy of educational institutions. [20-22]. At the same time, the multilingual space for a international student goes far beyond the scope of the educational institution itself and communication with other people. Interpersonal and group communication is the most obvious part of multilingual space, however material culture of multilingualism is the additional part of space where international students exist. [23] Moriaty notes, that language of material objects often provides very accurate account of the living sociolinguistic reality.

Thus, multilingual space for international student can be divided into space of communication and "material space of language" (tangible objects). Ou and Gu use the term "translocal space" to describe communicative interaction of international students with different language background [24]. Miller proposes to study how spaces are constituted and the kinds of legitimate, desirable, and possible linguistic acts [25].

The physical space of the language is extremely diverse and represented by different elements of material culture. Linguistic landscape formed by languages in the public space is a popular area of research [26-28]. Linguistic landscape was originally interpreted as "the language of public road signs, advertising billboards, street names, place 
names, commercial shop signs, and public signs on government buildings combines to form the linguistic landscape of a given territory, region, or urban agglomeration» [29]. Nowadays this notion is expanding by many researchers till «images, photos, sounds (soundscapes), movements, music, smells (smellscapes), graffiti, clothes, food, buildings, history, as well as people who are immersed and absorbed in spaces by interacting with Linguistic landscape in different ways» [30]. However, the linguistic landscape makes up only a small part of the language represented in material objects [31, 32]. Material culture includes a vast variety of objects, from food and kitchen utensils, through furniture, technical devices, stationery and books, to buildings and monuments $[33,34]$. Multilingual space can be analyzed in different contexts: private, public, commercial, or media [35]. Many authors point out the importance of considering scale for multilingual space analyzing $[17,24]$. According to the proposed vertical division of the language space by Blommaert [36], we offer to distinguish 3 levels of space for a student: mega - city level, meso - university level, micro - individual level (Figure 1)

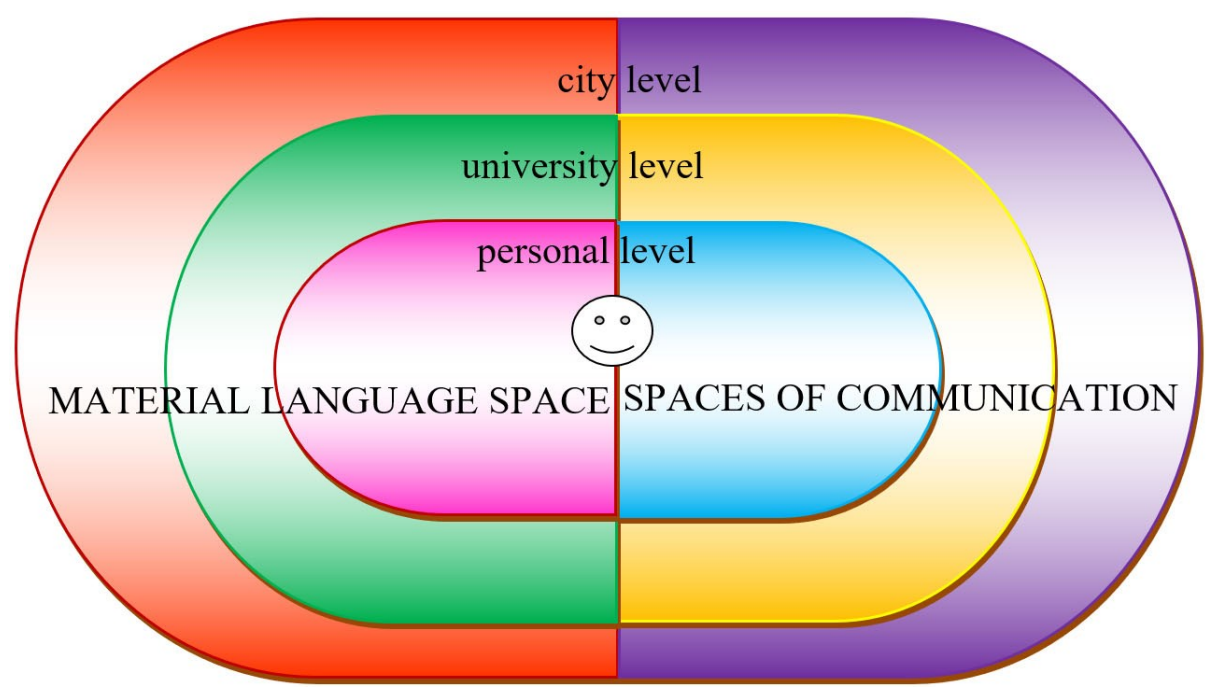

Fig. 1. Multilingual space segments from the student's perspective

The three levels of the physical space of the language are heterogeneous and have different effects on a person. The part of the material city environment that usually called the linguistic landscape (pointers, signboards, signs, etc.) helps to orient oneself in the surrounding space. As a rule, it is motionless and the reader has enough time to get acquainted with it. Although some part of the linguistic landscape can move, for example, together with vehicles or stickers, pamphlets, banknotes [37]. In any case, existing in a foreign language, it cannot fulfill its functions for a foreign student.

The physical university space consists of signs and objects on the territory of the university and of material mediums of educational information (textbooks, synopses, control tasks, exam tickets, etc.). The material personal linguistic space of international 
students is initially saturated with their native language, since it contains objects from their homeland. Nevertheless, penetration of the Russian language naturally occurs.

The space of communication also has its own characteristics at each of the levels. The communicative space at the mega level is the least saturated. It exists from time to time, but its importance is extremely high, since communication serves certain specific purposes and should lead to a specific result. The meso level is much richer. Learning is directly related to the language of study. However, the student usually has time to figure it out and make a decision, all the consequences are delayed. The exception is administrative matters and official documents. At the micro level, communication with the closest circle often occurs in the student's native language, as it happens with compatriots.

It's impossible to ignore the technical component, which today often acts as an intermediary between the language space and the foreign student. Horváth notes that transcultural communication is becoming possible in the digital age [38]. Existing online translators and applications can act as intermediaries in interpersonal communication and while reading information on physical objects. The development of AR technologies makes it possible to create an individual language space that will be superimposed on the physical environment. In this case, a multilingual cityscape turns into a monolingual version of the language creating "parallel multilingualism" [39].

\section{$2 \quad$ Materials and methods}

A foreign student is an object of this research. Coming into the foreign country, he is forced to assimilate new cultural patterns for successful functioning as a member of the host community. It is important to understand how the adaptation process of foreign students goes, what difficulties they face. A qualitative approach makes it possible to obtain an expanded interpretation of each of the factors, and thus a deeper understanding of the foreign students' problems.

The research methodology is empirical in nature and is represented in included observation, analysis of everyday life by factual data grouping. The study consisted of two phases. In the first phase 68 Chinese students were asked to write an essay about the difficulties of multilingual space. The study involved 1 st year undergraduate and graduate students. Graduate students had not previously studied at Russian universities, therefore, for the entire group this was the first semester of study in the Russian Federation. Since the students spoke Russian at a fairly low level, the works were partially or completely presented in Chinese or were performed with the help of an electronic translator. After the initial processing of the essay, it was revealed that students do not fully distinguish differences between linguistic problems and multilingual space problems, sometimes focusing on language difficulties. It was possible to display the multilingual space as much as possible through the eyes of a Chinese student who does not yet speak Russian sufficiently, thanks to the included observation carried out at the second stage. The level of Russian language proficiency and the importance of displaying all objects of the multilingual environment in which the student found himself in 
the learning process made significant restrictions on the study. Thus, only the chosen method made it possible to get the best understanding of the problem under study.

The data collection process took place in the 2019/2020 academic year among Chinese students studying at the St. Petersburg Polytechnic University. Two stages of the study were carried out. The first was in the form of the essay (the essays were supplemented with a short demographic questionnaire). Then after identifying the need for further detailing of the obtained primary information included observation was performed. The resulting data was decoded and analyzed based on constructed multilingual space model.

In this work, we used interdisciplinary approach, which allowed us to consider the Multilingual space as a complex social phenomenon from the perspective of the sociology of communication and sociolinguistics. In addition, such methods of scientific research as the construction of logical circuits, graphic interpretation of theoretical information and empirical data were used.

Examples illustrating results of the study are anonymized in terms of students' names, and any other references that may identify an individual. Ethical approval was received from the Ethics Commission founded in the Institute of Humanities, Peter the Great St. Petersburg Polytechnic University, which is ruled by the code of ethics of the Russian Society of Sociologists.

\section{$3 \quad$ Results}

Using qualitative and unstructured methods instead of traditional surveys, we aimed to identify the concept of multilingual space through the eyes of a Chinese student and to mark key points and challenges. To provide a general picture, the urban and university levels also include a general description of the language environment. The key points of the language environment correspond to information received from students as visual cues during included observation or from the essays.

\subsection{Multilingual space levels}

Saint-Petersburg as a multilingual center: general characteristics. St. Petersburg is one of the most attractive cities for foreigners in Russia. By 2018, more than 28.2 thousand students are studying in St. Petersburg, which is $9.35 \%$ of the total student population [40]. Most of the students are natives of China and Kazakhstan (there are also students from Uzbekistan, Ukraine, Tajikistan, Kyrgyzstan, Turkmenistan, Moldova, Azerbaijan, Armenia, Mongolia, Iran, India, Iraq, Egypt, North Korea and other countries). China has developed into the world's largest source of international students [41].

St. Petersburg turns out to be saturated with different languages, multilingual conversations, signs, symbols, announcements, objects with inscriptions in different languages which represent the multilingual space of the city. The opinion about this space of a person from another country, especially who came not for a week accompanied by a guide, but for a long time is of particular interest. Young people from China who 
came to get education in Russia are very important in this sense because they have the experience of a long stay in St. Petersburg, moreover the Cyrillic and Latin spelling that exist in the multilingual space are alien to them [42].

With the dominance of the Russian language in St. Petersburg, English is widely used. Announcements, information signs, signboards, street names, especially in the central part of the city, usually have English translation, which reflects the global trend in urban centers, where English is used as a lingva franca, associated with modernity, internationalism, technological advancement or creative lingustics [39]. Most ATMs have an English menu.

In the physical space of the city, the Chinese language is presented only in the most significant tourist points of the city: the airport, central stations and ports, several central museums like the Hermitage. In the latter other languages are also used, albeit to a lesser extent. In 2006, it was proposed to translate the street names into Chinese, but in the end, the project was not implemented. Some cafes and shops, banks and even pharmacies in the tourist center of St. Petersburg use the Chinese language on their own initiative on signs, advertising media and shop windows. Inside you can find menus, travel brochures, loyalty card questionnaires and others in Chinese.

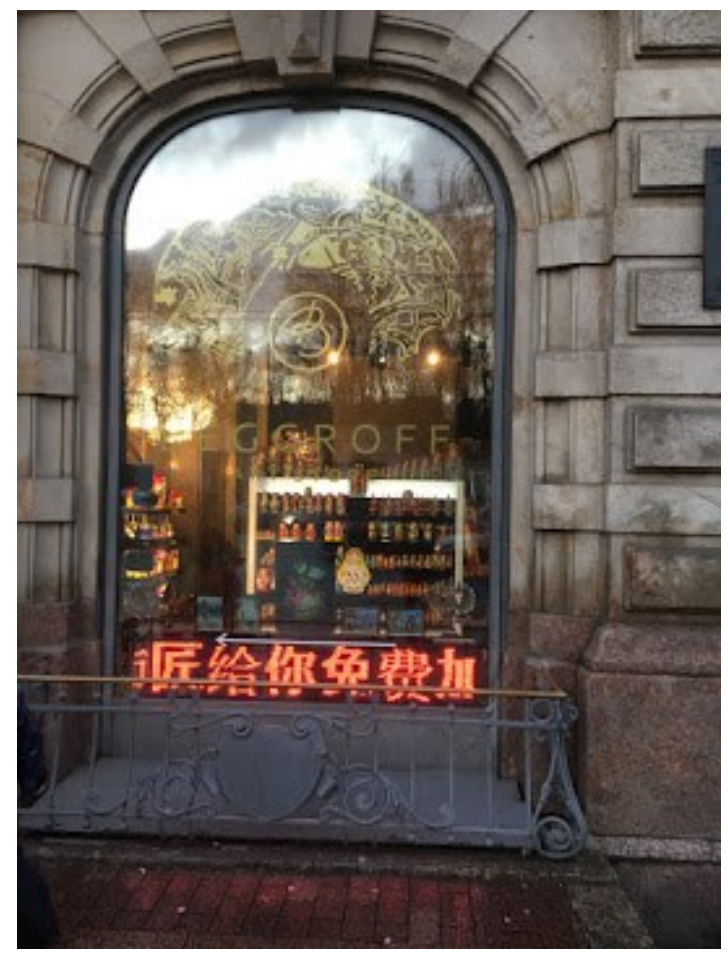

Fig. 2. Chinese in a souvenir shop on Nevsky Prospect. 


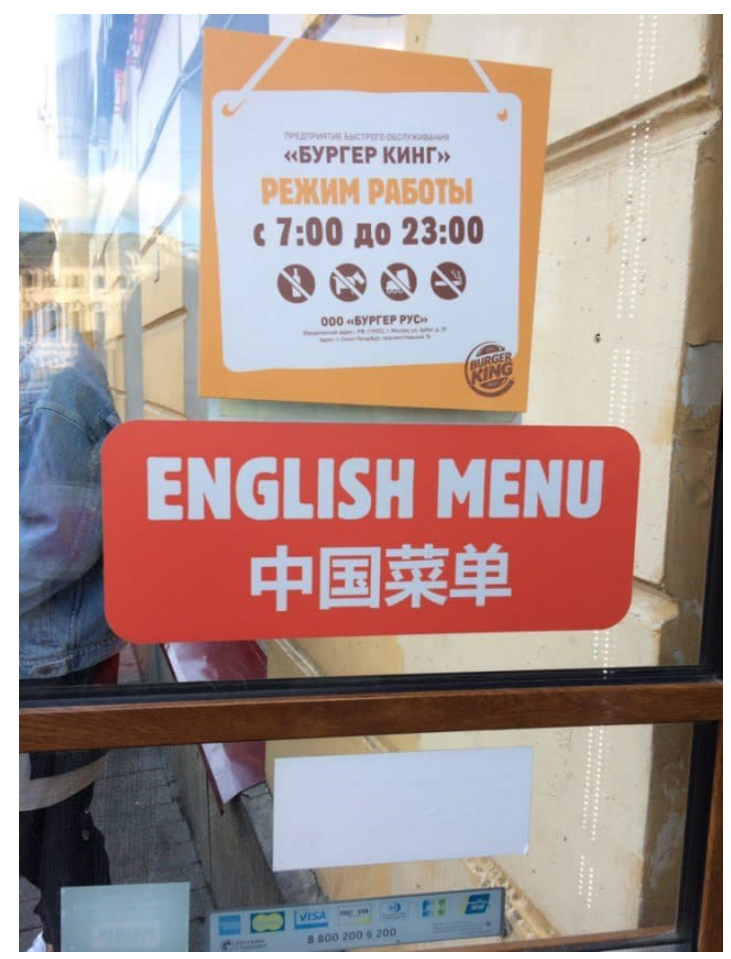

Fig. 3. Signboard in the snack-bar "China menu" (instead of the Menu in Chinese)

Quite often complicated Chinese hieroglyphs, which are no longer used on the mainland China we see in the signs. Nevertheless, big mistakes (like the Moscow sign, where instead of the hieroglyph for Red Square, the hieroglyph 红肠 meaning "red gut" appeared) are not common.

Since 2016, the information board at the international airport has had a Chinese version in addition to Russian and English and a number of information signs are also duplicated in Chinese. Voice messages for departures to China and Moscow have also been dubbed in Chinese since 2016. At the airport there are employees who are able to communicate in Chinese and everyone speaks English. However, it is not easy for foreigners to explain themselves in the city. In this regard, requirements for salespeople in central department stores include knowledge of the Chinese language. Several major museums offer guided tours and audio guides in Chinese. According to the survey of the Russian Public Opinion Research Center [43], 63\% of Russians can explain themselves in English (no more than 6\% are fluent in the language; in St. Petersburg this figure is slightly higher at $13 \%$ ) and in Chinese $6 \%$. The chances of speaking Chinese in an urban environment are extremely low.

City multilingual space through the Eyes of a Chinese Student. For a Chinese student, St. Petersburg is not limited to a tourist center. The multilingual space of the city turns out to be a challenge for a young man. Students must solve numerous problems: getting to a place, eating, changing money, making purchases. All these actions, 
performed quite easily even in an unfamiliar place, but in the space of the native language, in a new language environment, often become a problem. The huge city turned out to be dumb for the arriving Chinese students. The physical language space, which serves as a source of constant clues for native speakers, is an insoluble puzzle for the Chinese. People around them turn out to be a more promising option for clarifying misunderstandings, but students describe that they often have to ask different people (more often how to get through, drive, locate) before they overcome difficulties. In a number of cases, help was provided by people who volunteered to assist themselves. Students often use translation programs and English if they speak fluently. In the most problematic situations, their compatriots help and become linguistic intermediaries.

Judging by the analyzed essays, the problems of Chinese students at the mega level began already at the airport. Some of them did not find signs in Chinese, others could not find luggage or transport. Most of the respondents, in one context or another, described what happened on the first day of their stay in St. Petersburg as a problem. Most often they recalled the road, the stress associated with the need to communicate with the taxi driver when they didn't manage to explain the address, the numbers or street etc. It is obvious that transport, and in particular the metro, is a big problem for students. There is no Chinese language in the St. Petersburg underground. The Russian and English languages are present on tangible media, station announcements are made in Russian. Therefore, many students complained that they did not come out at their station and could not get to the transfer point, etc.

Students with poor language skills initially tried to minimize communication with the urban environment, looking for support in the team of compatriots. They visited different places in the case of extreme necessity: illness, purchase of warm clothes due to the unexpected harsh climate, etc. Traveling around the city was limited to walking or taxiing. Although the latter option was also treated as problematic because they had to use the application to order the taxi, to speak with the driver personly or by phone. Nevertheless later students began to explore the urban environment, facing challenges in cafes, canteens and shops. Far from the city center, all information given on price tags, menus, signs is presented only in Russian, often with abbreviations, sometimes in handwritten form creating problems of finding the right product and shopping unnecessary things, etc.

In addition to cases when students acted by their own free will, problems were raised by situations when something was required of them. Questions addressed to young people in Russian most often had no chance of being answered. One young man, who decided to answer "yes" to everything, encountered problems already at customs when he was asked to take off his glasses. The use of this strategy in stores by other students resulted in unnecessary purchases of at least a package. If direct communication in rare cases had a chance of success, then telephone conversations were ended in fiasco. If it was necessary to communicate with a doctor, the situation was further complicated by using specific vocabulary required to describe the problems and to understand the doctor's recommendations.

In general, for Chinese students the greatest difficulties in the urban language space are caused by transport - mentioned in $52 \%$ of essays ( $49 \%$ - metro, $31 \%$ - taxi, 17\% - 
airport), shops and restaurants - 46\%, visiting a doctor - $22 \%$; apartment rent - $13 \%$; location determination - $10 \%$; currency exchange $-6 \%$.

University multilingual space. Meso level of the student's language space is represented by the university with the dominance of the Russian language. In SPbPU, English duplication of information is available only in several points of the university (for example, in the main building of the university there is an English version of information about administrative positions). There are signs and announcements in Chinese only in one building, where foreign student's administrative services, hostel for foreign students and a number of classrooms are located. However, even here it is traditional to duplicate information only in English (Figure 4). Chinese is used in actual posters (Figure 5).

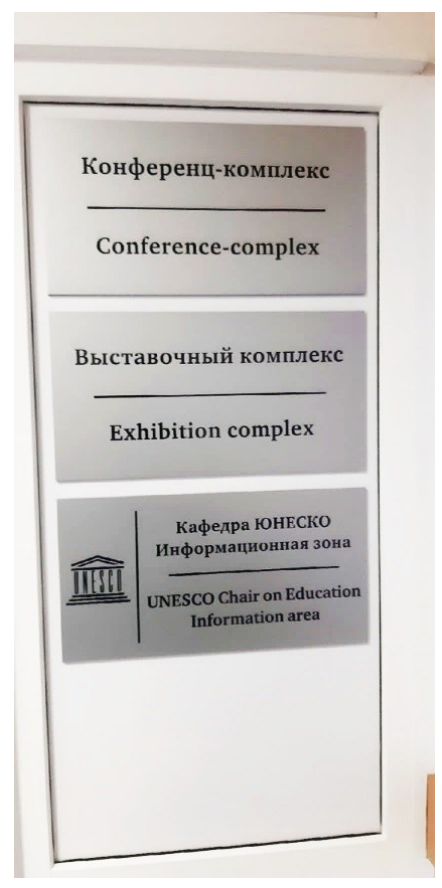

Fig. 4. Signboard (Russian and English)

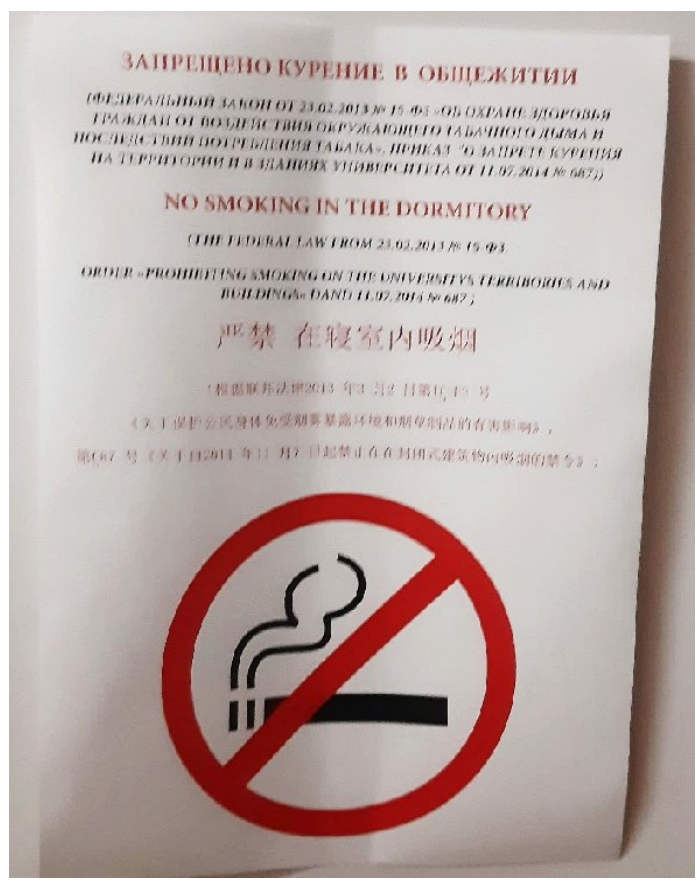

Fig. 5. Poster "No smoking" (Russian, English, Chinese)

Prompt announcements in departments working with foreign students may be written in Chinese by hand (Figure 6). It is notable that announcements in Chinese can differ significantly from information posted in Russian and English. 


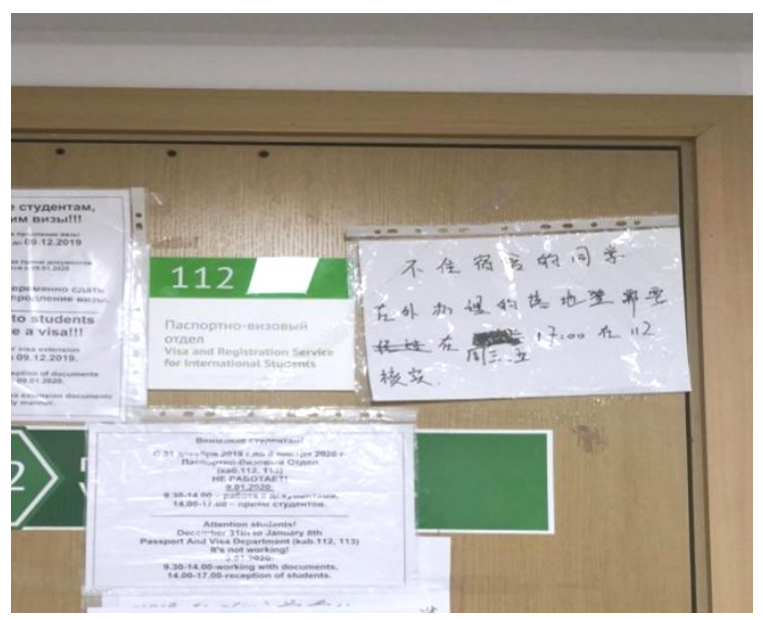

Fig. 6. Handwritten poster in Chinese

Russian and English inscriptions are usually identical. However in the example given below (Figure 7), Russian and English texts differ by the polite phrase "Thank you for understanding!" written in English.

The university language space requires significantly more language immersion, due to the active information exchange. However, stressful situations are less common here. The description of the potentially dangerous consequences of communication problems is not directly related to learning, but to the physical linguistic space. In this case, most often it is connected with the documents necessary for admission to the university, staying in a hostel, visas and migration cards, which are issued in Russian. Class schedules are not so problematic, but two students were at the wrong time and in the wrong class when they started learning.

Educational communication and teaching materials are in Russian. In both communicative and physical space, Chinese students strive to create a native language space around them. When completing assignments in the classroom, they are combined into a monolingual group. For the most difficult academic subjects they search additional materials in Chinese. Moreover, from the inside, the group is linguistically permeable, since usually in a group of Chinese students there is a leader who speaks Russian at a sufficient level to maintain communication with the outside world and transfer the most essential information to the rest of the group. On the contrary, from the outside, a group of Chinese students turns out to be practically impenetrable, communicating in their native language, the teacher or other students (except for a small number of teaching or studying Chinese) cannot find out if they are prompting their compatriot or discussing the menu in the dining room. 


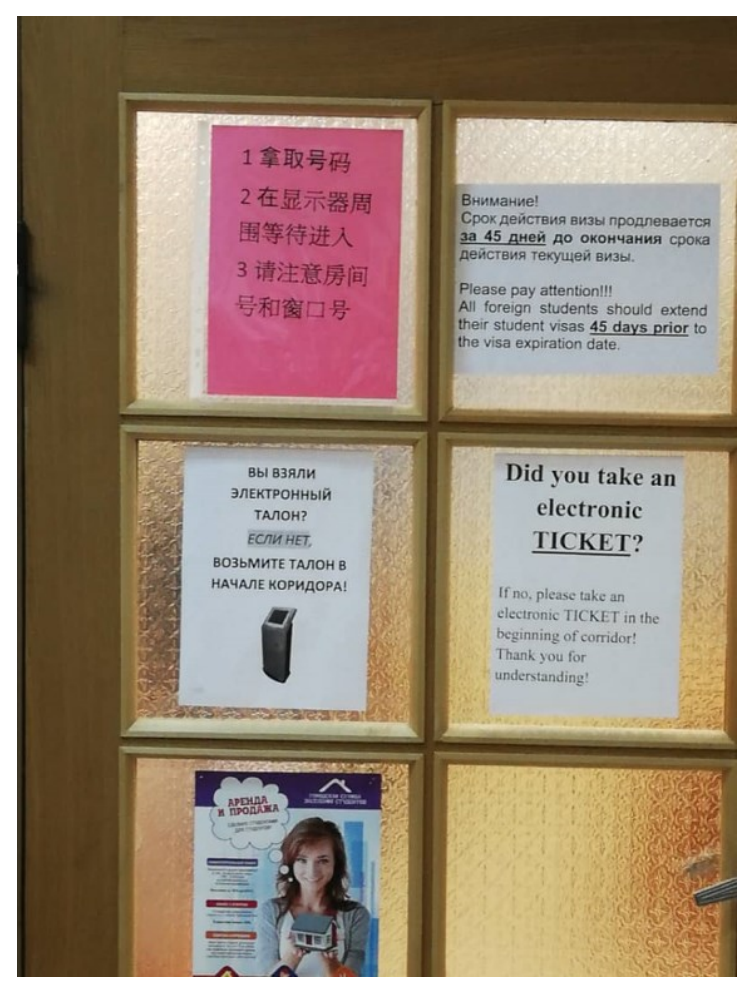

Fig. 7. Announcements in Chinese, Russian and English are not identical

However, at the mid-level, the influence of the Russian language on the international student is most active. It is required to understand what is stated by the teacher and to do different tasks in Russian.

At the material level, the greatest problems are caused by handwritten texts, which are difficult to decipher, since they differ significantly from the printed texts (most often, when a teacher writes on a blackboard (Figure 8 a), or students read notes of fellow students. Sometimes information is written for Chinese when they cannot explain themselves orally (Figure $8 \mathrm{~b}$ )). On the communicative level the fast speed of information delivery is a big problem. This level is characterized by the active use of online translators, but the results are often unsatisfactory, especially in the case of colloquial speech and special terms.

In general, among the main problems of Chinese students there are some difficulties associated with the university language space: the teacher's fast speech - mentioned in $25 \%$ of the essays, incomprehensible handwritten text $-22 \%$, problems with enrollment for an online course - $16 \%$, difficulties with documents - $13 \%$; misunderstanding of what the teacher says - $9 \%$ (which in most cases leads to the search for material in their native language), untranslatable terms - $6 \%$, inadequate work of online translators and dictionaries $-4 \%$. 


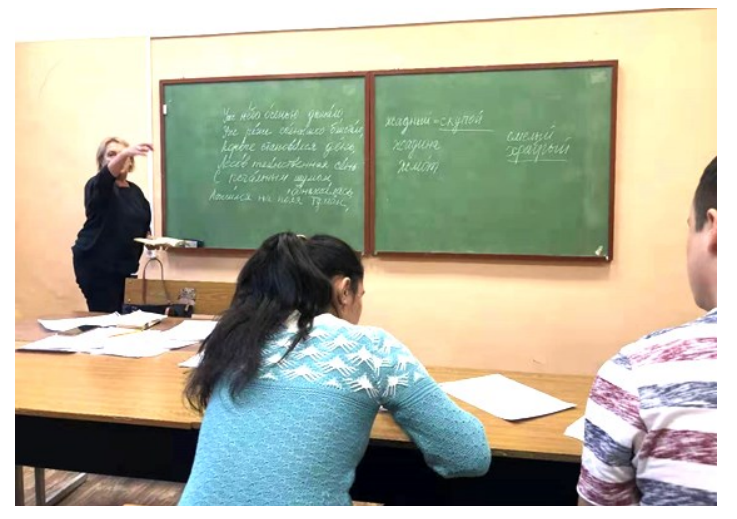

(a)

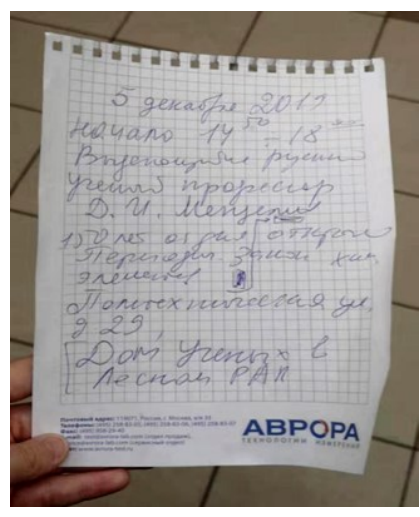

(b)

Fig. 8. Russian handwritten text (a) on a blackboard with chalk, (b) information about the event on a sheet of paper from the notebook

Personal multilingual space. Personal linguistic space of Chinese students is mostly saturated with their native language. They strive to communicate, live and enjoy the objects that create the Chinese space. Arriving in the city, students who have problems with Russian hide in this cocoon, which mediates all other interactions in the language space. It is typical for linguistic groups abroad [44].

Teachers notice that international students in classes tended to stick together. This sense of community was especially typical for the students coming from China, Uzbekistan, Turkmenistan [45]. Students tries to live together in dormitories.

It is typical for foreign students to work together on assignments and share materials. Those who live together in a hostel are united by language groups (Chinese, Turkmen). Close Internet communication is constantly maintained with fellow students, compatriots. Besides, in social networks they can keep in touch with friends and relatives who have remained at home. This trend is observed in numerous studies [46-48]. In Figure 9 we show a fragment of a WeChat conversation created for intra-group communication by Chinese students. Messages are in Chinese and educational materials in Russian are attached. 


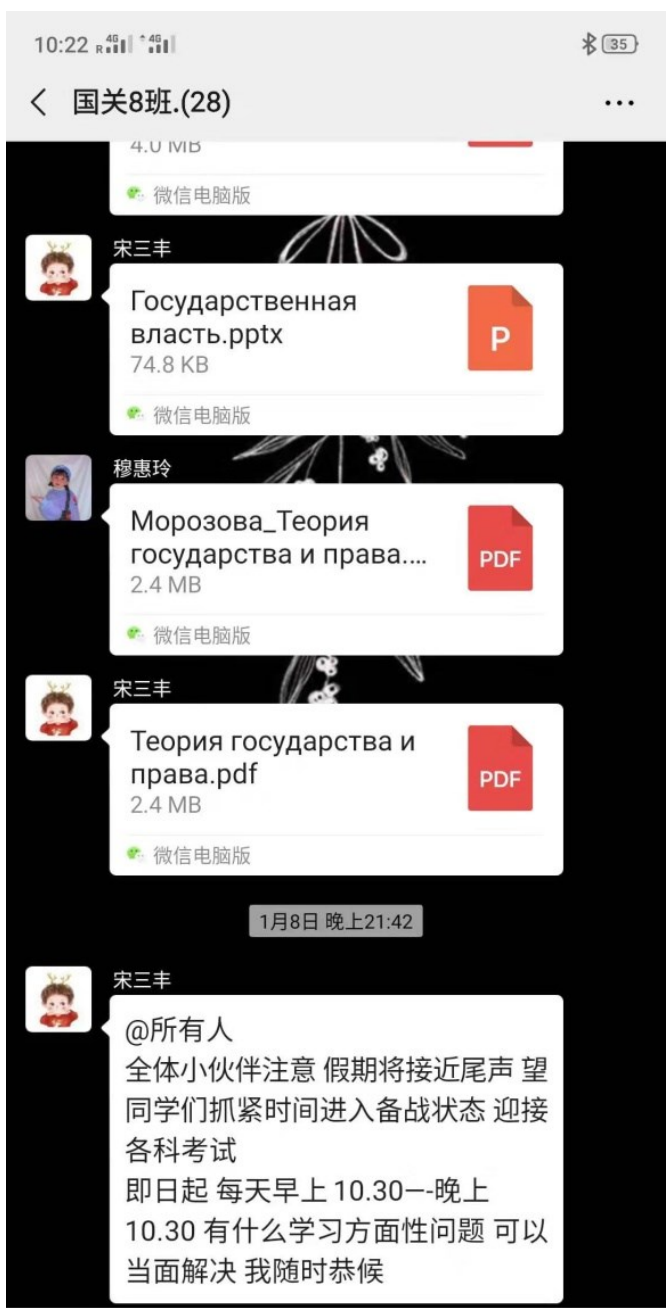

(ग))

(:) $\oplus$

Fig. 9. Chinese students' chat for educational information exchanging

It is clear that even despite the resistance, the Russian language and partly English penetrate into physical space. First of all, educational subjects are tightly connected with linguistic aspects: Russian dictionaries, textbooks, learning materials, notes, student card, student's record book etc. Items with Russian and English inscriptions appear, replacing native: stationery, cosmetics, cards, etc.

Sometimes Russian food appears, but in St. Petersburg, Chinese students also prefer to look for their native cuisine, which is reflected in the language of the packaging. Many students have Chinese tea at home (examples of inscriptions - 泥潭翠芽, 洛神 
花 专业调配组合花茶), snacks (大刀肉, 朝平脆哨, 网红三千丝 松鼠糖糖, 大娱大 肉), noodles (康师傅 老坛酸菜牛肉面), sauces (三养辣火鸡味调味酱) and other products as well as Chinese sticks (Figure 10). However, there are edible items of a shorter shelf life with Russian and English inscriptions (for example, dairy products, juices, bakery products, etc.) It is interesting that, when photographing food packages, the student placed most of the Chinese inscriptions conveniently for reading. Packages with Russian and English he put across, that may indicate that he is less inclined to view them as readable.
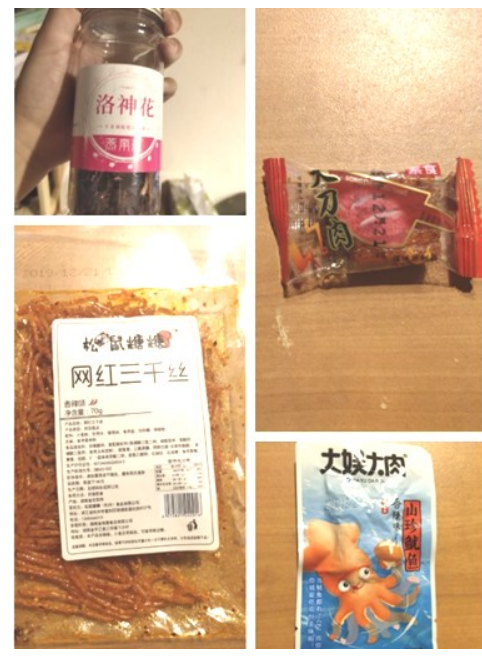

(a)

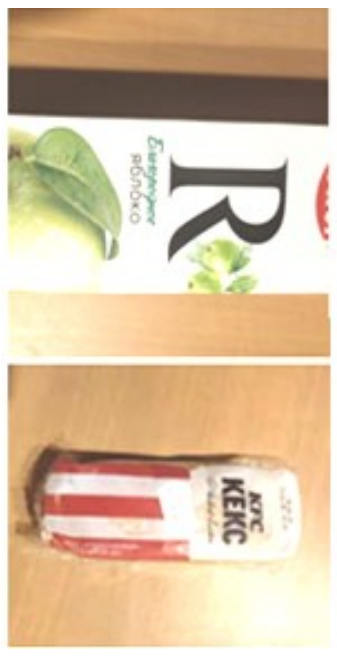

(b)

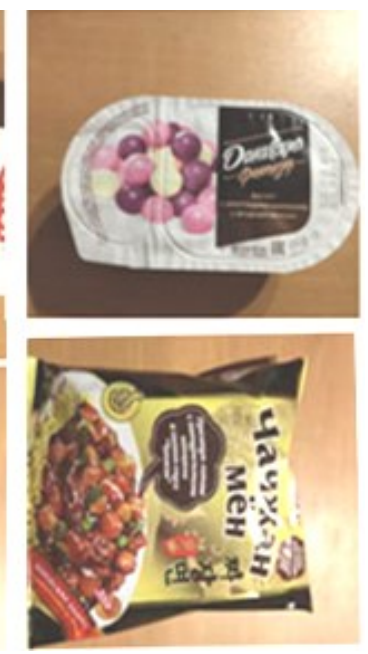

(b)

Fig. 10. An example of student's various food which becomes a material mediator of (a) Chinese (b) Russian and English

The subject of material culture often appearing in personal space and causing the greatest problems is the Russian keyboard, which is required to complete assignments and maintain communication with teachers and group mates. Students complain that they get used to the lettering very slowly, making it difficult to do homework and chat.

In the field of personal communication space, acquaintances are gradually being made, activating the Russian language. However, the essay quite often indicates the problem of rapprochement with Russian-speaking youth, primarily among fellow students due to their poor knowledge of the language in general (and in particular because of their quick speech, jokes, use of slang or well-established language constructions). Nevertheless, there are happy endings of the stories of making friends, which immediately significantly increased the flow of Russian-language communication in the personal space.

Thus, the two biggest problems of the personal language space are the use of keyboard ( $9 \%$ of all essays), and the difficulties in establishing friendly relations with Russian-speaking youth (12\%). 
Problems at different levels of the multilingual space - summary. Analysis of the multilingual space of a student's life at different levels allows one to see both linguistic dominance and communication trends, and the most problematic aspects in terms of language. For Chinese students who come to St. Petersburg, for a long time the microlevel remains a space of the native language where material objects of the Russian and English languages slowly penetrates and hardly replace Chinese. Communication acquires a Russian dimension when local friends appear.

The meso-level, represented by university life, immerses the student to the greatest extent in the Russian-speaking space. Both material media and communication flows require from international student to be constantly involved in using the language. The mega-level does not have such a strong influence on the student. Some students even initially use avoidance tactics, minimizing collisions with the urban environment. Nevertheless, life requires interaction with the transport network, purchasing goods and services. Problems arising at this level require a quick solution, therefore they are sometimes perceived painfully.

In Figure 11 we show a number of problems for students at each of the multilingual space levels, related either to the physical or communication space. So we see that at the mega-level, almost any type of communication is painful no matter who the students communicate with (a doctor, salesman, taxi driver). It may become a serious problem to foreign students. At the meso-level, communication is no longer a significant problem. Though there is a huge flow of Russian-language information at this level, the perception of which is difficult primarily due to the fast pace. The micro-level is interesting because, being essentially Chinese it tends to acquire a Russian-speaking dimension containing close communication with local youth.

The physical space also poses some challenges. In some cases, it is the texts that play a key role in the implementation of a particular activity. At the macro level, making purchases in shops and food outlets is hampered by difficult-to-translate explanations (in particular, on price tags, in the menu, etc.). The mesoscale - university linguistic space is the most saturated with information, and creates a problem in the form of material presentation (handwritten Russian text). The difficulty of understanding it prevents the use of local students' learning materials, as well as the inscriptions made by the teacher during the class. The most difficult subject of the micro-level of the physical language space is the Cyrillic keyboard required for Russian-language typing.

The hierarchical structure and division of the multilingual space allowed creating a multilevel linguistic portrait of the city from the point of view of an international student. This model can have practical application in educational institutions' practice and in the city authorities activities increasing the urban communication attractiveness. 


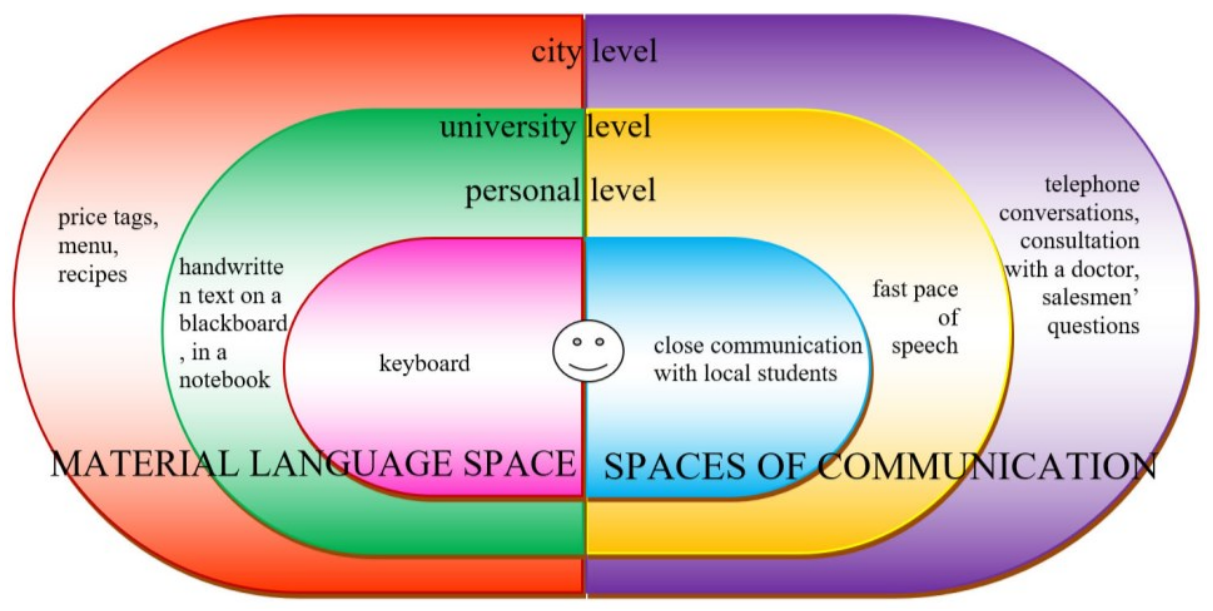

Fig. 11. The main problems of a student at different levels of Multilingual space

\subsection{Digital solutions for Chinese students adaptation to the multilingual space}

The identified key challenges in the multilingual space for Chinese students serve as benchmarks for establishing baselines to support their adaptation. The university's ability to influence multilingual space appears to be a limited physical university space, but information and communication technologies expand multilingual space, opening it up to a digital dimension that can have a supportive effect in an unobtrusive, familiar form. The importance of the digital component for the adaptation of foreign-speaking people is shown in a number of studies [32,49-51]. There is also a positive experience of using social media and blogging to grow intercultural competence $[16,52,53]$. However elaborated policy of digital multi-lingual adaptation of international students is a question of the future.

We can describe some areas of work at different levels of the multilingual space. The multilingual space challenges of the city level are the first that Chinese students face upon arrival in St. Petersburg, that is why preparation for them should begin in China. For young people entering the St. Petersburg Polytechnic University, a web booklet has been developed, the purpose of which is a brief and colorful preliminary acquaintance with the linguistic realities of the city with photographs of the airport, transport, and the university building. It also contains links to useful resources (for example, a subway map in Chinese). Since modern youth have problems with comprehension of big text information, in addition to the emphasis on visual presentation, there is also some ways to get acquainted with the urban realities in the form of online quests. Game methods of communicating with applicants are being used by Russian universities. In Minecraft, besides SPbPU, there is the Higher School of Economics, St. Petersburg State University, ITMO University, etc.

The use of the Chinese language in the campus is a result of a systematic educational policy that expands multi-lingualism in learning and in everyday life and thanks to spontaneous initiative of university staff and students. 
Inscriptions in Chinese are increasingly embedded in the material culture of the university, hieroglyphs can be found in the clinic, in the offices of teachers and dean's offices. Resource Center for Chinese Students functions in Peter the Great St. Petersburg Polytechnic University. Initially, only Chinese undergraduate, graduate and postgraduate students volunteered at the center. The main function of the Center is to support the adaptation of Chinese students during the preparatory cycle and undergraduate courses. Center employees are intermediaries in communication between students and representatives of the administration, academic departments, dormitories, etc. In addition, they help Chinese students with their homework and provide extra classes of Russian as a foreign language with explanations in Chinese. At the same time, the Center is not an educational unit. The activity of the center is built into the structure of additional work with foreign students and is only supervised by teachers of the Russian language, who provide methodological support to the employees of the center who conduct classes. At present time, Russian students of SPbPU who study the Chinese language also take part in such activities. With the introduction of bilingual communication, the efficiency of interaction between the center and administrative structures has increased. Teachers who teach Chinese students also note a positive trend.

A number of bilingual Russian-Chinese textbooks have been published in university: in philosophy (the most difficult discipline for Chinese students), in higher mathematics and probability theory etc. While studying this cources almost all students, regardless of cultural background, experience difficulties. The SPbPU website https://chinese.spbstu.ru/ (Figure 12) and the e-education portal Openedu have a Chinese version.

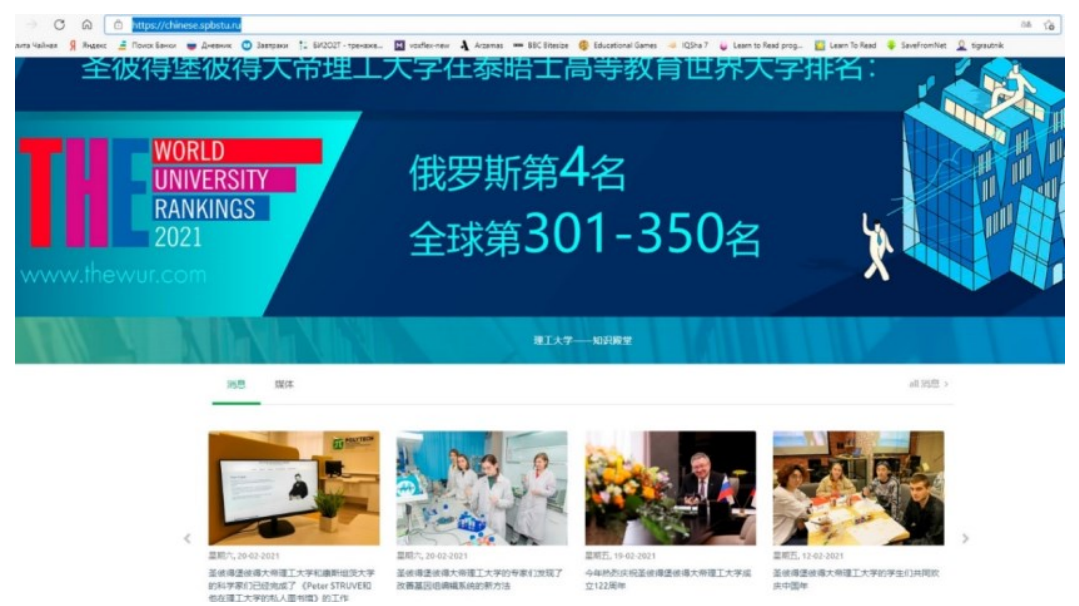

Fig. 12. Chinese version of the website of the St. Petersburg Polytechnic University

The augmented reality application is another opportunity to expand the multicultural space through the digital component. In Figure 13 you can see a video fragment of a linguistic addition to the university spaces. Besides possibility of linguistic prompts in various places of the dormitory, campus and in the nearest neighborhood, which can make material linguistic objects multilingual, such an application serves to reduce stress, as comic advice is given by funny characters. 


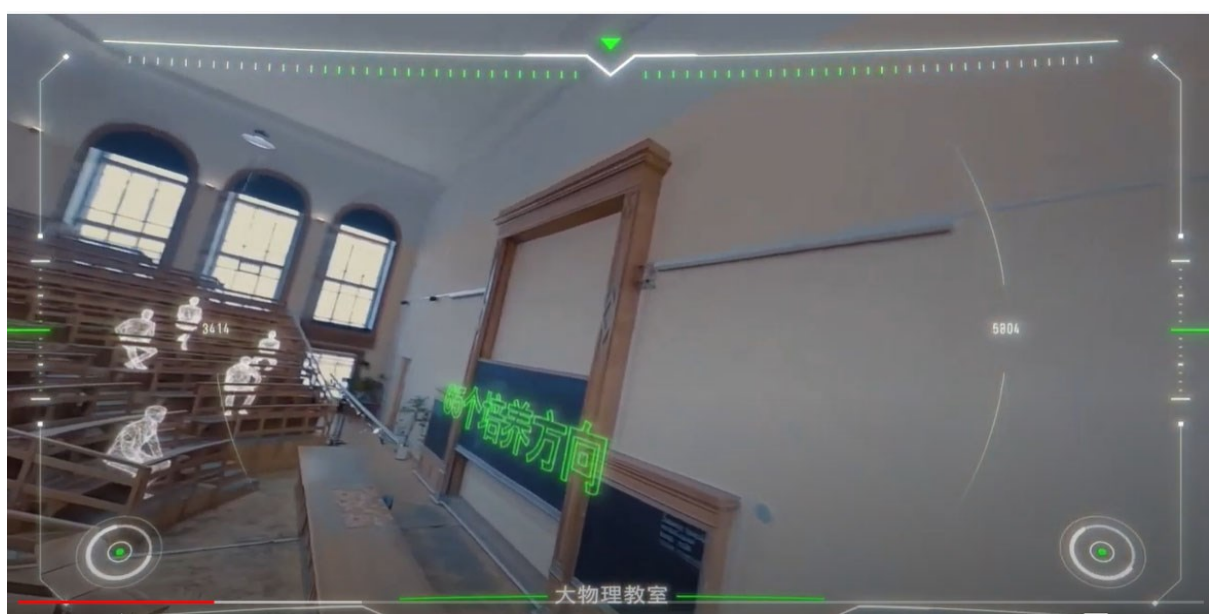

Fig. 13. Virtual linguistic augmentation of university environment [54]

The personal level is the most difficult to influence, but digital solutions can solve the problems in this area especially in the social networking space. One of the factors that appears in the Personal level is interpersonal communication, which causes numerous difficulties. Even mediated by digital resources and automatic translators, communication with teachers and fellow students is difficult for students from China. Personal communication, Russian handwriting, funny language traps, common translation errors can serve as the theme of comics, demotivators and memes for a special multilingual public, which is useful for international and Russian students studying languages. Figure 14 shows an example of a meme based on a question from a student who used the automatic translation from Chinese and, instead of asking when the exam would be, asked when there would be makeup.

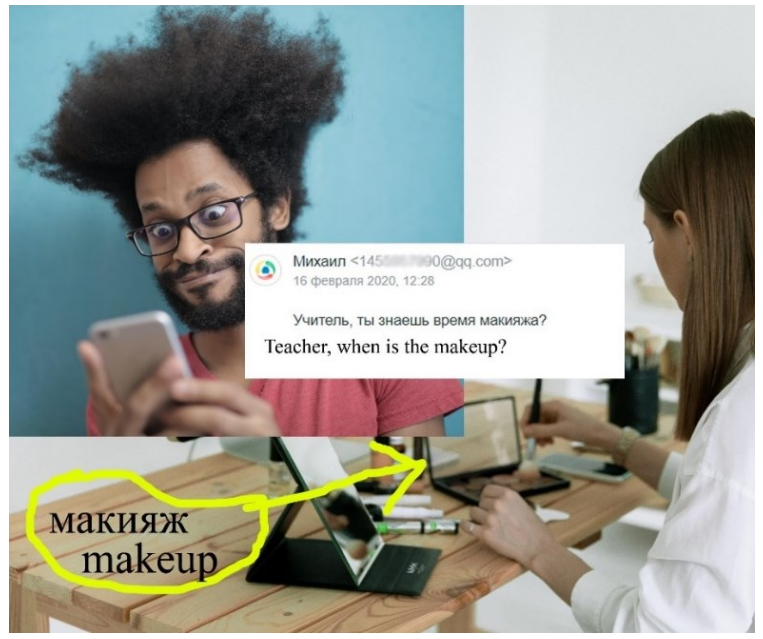

Fig. 14. Meme illustrating an error when using automatic translation from Chinese 
The proposed multilingual space model serves as a benchmark for identifying the network of factors that make up challenges for international students. For some of them, complex solutions are possible that can significantly reduce "culture shock". Others cannot be solved in the short term because adjustment of international educational policy is required.

\section{Discussion}

Living and studying in Russia for young people from China usually requires serious adaptation to an alien cultural environment. Language has traditionally been considered as a significant factor of intercultural competence, but the proposed model suggests changing the traditional view of language as an ability of students [15, 16, 55-57] to a multilevel system of multilingual space, into which they are embedded. Recognizing the big role of learning the country's language [20-22, 58, 59], special adaptation courses and pedagogical techniques [60-65] in the context of students' intercultural competence development, we left education outside the scope of this study, focusing on the multilingual space. Interaction with this space in many aspects becomes a challenge for international students. However, in the future, the multi-level assessment of the multilingual space may become one of the guidelines for educational policy.

An analysis of the multilingual space of St. Petersburg through the eyes of Chinese students studying at SPbPU reveals many complexities. Although St. Petersburg as a tourist city has a pronounced multingualism, and $\mathrm{SPbPU}$ is one of the leaders among universities in terms of the number of Chinese students, the Chinese language occupies an insignificant place in the multingual space. This case together with the difficulties associated with the perception of Cyrillic and Latin spelling, creates a rich material for analysis. In this research the authors identified problems, emphasized by many scientists [44, 45, 66, 67], associated with the material culture of multilingualism. The ability to focus on many factors linked into a single unit allows us to build the adaptation system for Chinese students.

The article proposes some ways to overcome the challenges, in particular, expanding the multilingual space due to the digital component. It really can greatly facilitate overcoming the initial adaptation challenges. The proposed projects and examples do not take into account peculiarities of the students' attitude towards foreign social networks. As a rule Chinese young people are accustomed to local networks[68] and have special network behavior [69-71].

\section{$5 \quad$ References}

[1] Berg M. Vande, Paige R.M., Lou K.H. (2012). Student Learning Abroad: What Our Students Are Learning, What They're Not, and What We Can Do about It. Stylus, Sterling, VA. https://doi.org/10.1353/rhe.2013.0039

[2] Jackson J. (2018). Interculturality in international education. Routledge, London

[3] Deardorff D.K. (2015). Demystifying Outcomes Assessment for International Educators: A Practical Approach. Stylus, Sterling, VA 
[4] Zhao X., Ding S., Kalashnyk L., Luhova T. (2020). Cultural Adaptation of Chinese Students as the Need of Their Education Abroad Process. Soc Integr Educ Proc Int Sci Conf 4:388 . https://doi.org/10.17770/sie2020vol4.4856

[5] Roberts C. (2002). Ethnography and cultural practice: Ways of learning during residence abroad. In: Alred G, Byram M, Fleming M (eds) Intercultural Experience and Education. Multilingual Matters, Clevedon, pp 114 - 129. https://doi.org/10.21832/9781853596087$\underline{011}$

[6] Xi H. (2020). How Do Chinese Students Adapt to Live Overseas? J Contemp Educ Res 4: . https://doi.org/10.26689/jcer.v4i11.1644

[7] Bochner S. (2003). Culture Shock Due to Contact with Unfamiliar Cultures. Online Readings Psychol Cult 8: . https://doi.org/10.9707/2307-0919.1073

[8] Shen L., Chen J. (2020). Research on Culture Shock of International Chinese Students from Nanjing Forest Police College. Theory Pract Lang Stud 10:898 . https://doi.org/ $\underline{10.17507 / \mathrm{tpls} .1008 .07}$

[9] Lin C. (2006). Culture Shock and Social Support: An Investigation of a Chinese Student Organization on a US Campus. J Intercult Commun Res 35:117-137 . https://doi.org/10. $1080 / 17475750600909279$

[10] Kim Y.Y. (2008). Intercultural personhood: Globalization and a way of being. Int J Intercult Relations 32:359-368 . https://doi.org/10.1016/j.ijintrel.2008.04.005

[11] Jackson J. (2008). Globalization, internationalization, and short-term stays abroad. Int J Intercult Relations 32:349-358 . https://doi.org/10.1016/j.ijintrel.2008.04.004

[12] Nussbaum M. (2006). Education and democratic citizenship: Capabilities and quality education. J Hum Dev 7:385-395

[13] Tian M., Lowe J.A. (2014). Intercultural Identity and Intercultural Experiences of American Students in China. J Stud Int Educ 18:281-297 . https://doi.org/10.1177/1028315313496582

[14] Kazaryan R. (2021). The Concept of Anthropotechnical Safety of Functioning and Quality of Life. In: Murgul V, Pukhkal V (eds) International Scientific Conference Energy Management of Municipal Facilities and Sustainable Energy Technologies EMMFT 2019. EMMFT 2019. Advances in Intelligent Systems and Computing, vol 1258. Springer, Cham, pp 759-767. https://doi.org/10.1007/978-3-030-57453-6 68

[15] Byram M. (2008). Intercultural citizenship and foreign language education. Recuper el 20:122-132

[16] Elola I., Oskoz A. (2008). Blogging: Fostering Intercultural Competence Development in Foreign Language and Study Abroad Contexts. Foreign Lang Ann 41:454-477 . https://doi.org/10.1111/j.1944-9720.2008.tb03307.x

[17] Blommaert J., Collins J., Slembrouck S. (2005). Spaces of multilingualism. Lang Commun 25:197-216. https://doi.org/10.1016/j.langcom.2005.05.002

[18] Tilley C. (1999). Interpreting material culture. In: Pearce SM (ed) Interpreting objects and collections. Routledge Taylor \& Francis Group, London, pp 67-75

[19] Wei L. (2011). Moment Analysis and translanguaging space: Discursive construction of identities by multilingual Chinese youth in Britain. J Pragmat 43:1222-1235 . https://doi.org/10.1016/j.pragma.2010.07.035

[20] Preece S., Martin P. (2009). Imagining higher education as a multilingual space. Lang Educ 24:3-8 . https://doi.org/10.1080/09500780903343070

[21] Manan S.A. (2020). Teachers as agents of transformative pedagogy: Critical reflexivity, activism and multilingual spaces through a continua of biliteracy lens. Multilingua. https://doi.org/10.1515/multi-2019-0096

[22] Ayan Ceyhan M. (2016). Co-creating Transnational Spaces for Multilingual Practices in Turkey's State-run Monolingual Educational System: Sabiha Necipoğlu School 
Ethnography. In: Bildung in transnationalen Räumen. Springer Fachmedien Wiesbaden, Wiesbaden, pp 149-162. https://doi.org/10.1007/978-3-658-09642-7 9

[23] Moriarty M. (2014). Languages in motion: Multilingualism and mobility in the linguistic landscape. Int J Biling 18:457-463 . https://doi.org/10.1177/1367006913484208

[24] Ou W.A., Gu M.M. (2020). Negotiating language use and norms in intercultural communication: Multilingual university students' scaling practices in translocal space. Linguist Educ 57:100818 . https://doi.org/10.1016/j.linged.2020.100818

[25] Miller E.R. (2012). Agency, language learning, and multilingual spaces. Multilingua 31: . https://doi.org/10.1515/mult-2012-0020

[26] Tang H.K. (2020). Linguistic landscaping in Singapore: multilingualism or the dominance of English and its dual identity in the local linguistic ecology? Int J Multiling 17:152-173 . https://doi.org/10.1080/14790718.2018.1467422

[27] Leimgruber J.R.E. (2019). Montreal's linguistic landscape: instances of top-down and bottom-up language planning. In: Lluch MC, Kailuweit R, Pusch CD (eds) Linguistic landscape studies: The French connection. Rombach, Freiburg im Breisgau, pp 163-174. https://doi.org/10.1075/11.00022.amo

[28] Backhaus P. (2006). Multilingualism in Tokyo: A Look into the Linguistic Landscape. Int J Multiling 3:52-66

[29] Landry R., Bourhis R.Y. (1997). Linguistic Landscape and Ethnolinguistic Vitality: An Empirical Study. J Lang Soc Psychol 16:23-49

[30] Shohamy, E., \& Ben-Rafael A. (2015). Introduction: Linguistic landscape, a new journal. Linguist Landsc 1:1-5

[31] Aronin L., Hornsby M. (2018).. Introduction: The Realm of the Material Culture of Multilingualism. In: Aronin, L. Hornsby, M. Kiliańska-Przybyło G (ed) The Material Culture of Multilingualism. Educational Linguistics, vol 36. Springer, Cham, pp 1-17. https://doi.org/10.1007/978-3-319-91104-5

[32] Aronin L. (2020). Multilingualism in the Age of Technology. Technol Lang 1:6-11 . https://doi.org/10.48417/technolang.2020.01.02

[33] Aronin, L., \& Laoire M.Ó. (2013). The material culture of multilingualism: Moving beyond the linguistic landscape. Int J Multiling 10:225-235. https://doi.org/10.1080/14790718. 2012.679734

[34] Aronin L., Hornsby M., Kiliańska-Przybyło G. (2018). The Material culture of Multilingualism. Springer, Cham

[35] Jaworski A., Thurlow C. (2010). Language and the Globalizing Habitus of Tourism: Toward A Sociolinguistics of Fleeting Relationships. In: The Handbook of Language and Globalization. Wiley-Blackwell, Oxford, UK, pp 255-286. https://doi.org/10.1002/ 9781444324068.ch11

[36] Blommaert J. (2010). The sociolinguistics of globalization. Cambridge University Press, Cambridge

[37] Sebba M. (2010). Discourses in transit. In: A. Jaworski, Thurlow C (eds) Semiotic Landscapes: Language, Image, Space. Continuum, London. https://doi.org/10.1017/ $\underline{\mathrm{s} 0047404511000959}$

[38] Horváth I. (2019). Linguistic Mediation in the Digital Age. Acta Univ Sapientiae, Philol 11:5-15 . https://doi.org/10.2478/ausp-2019-0022

[39] Gorter D., Cenoz J. (2015). Linguistic Landscape and Multilingualism. In: Language Awareness and Multilingualism. Springer International Publishing, Cham, pp 1-13. https://doi.org/10.1007/978-3-319-02325-0 27-1 
[40] The Results of the Work of the Committee for Science and Higher Education in 2018 and the Main Tasks for 2019 (2019). Adm. St. Petersbg. https://www.gov.spb.ru/gov/otrasl/ c science/current activities/speeches/6858/

[41] Lin L. (2020). The visible hand behind study-abroad waves: cram schools, organizational framing and the international mobility of Chinese students. High Educ 79:259-274 . https://doi.org/10.1007/s10734-019-00408-1

[42] Valieva F., Sagimbayeva J., Kurmanayeva D., Tazhitova G. (2019) The Socio-Linguistic Adaptation of Migrants: The Case of Oralman Students' Studying in Kazakhstan. Educ Sci 9:164 . https://doi.org/10.3390/educsci9030164

[43] Foreign Language: A Promising Investment? (2019) All-Russian Cent. Study Public Opin.

[44] Dervin F., Du X.Y., Härkönen A. (2018). International students in China: Education, student life and intercultural encounters. Palgrave Macmillan, Basingstoke, UK

[45] Anosova N., Dashkina A. (2020). The Teacher's Role in Organizing Intercultural Communication Between Russian and International Students. In: Anikina Z (ed) Integrating Engineering Education and Humanities for Global Intercultural Perspectives. IEEHGIP 2020. Lecture Notes in Networks and Systems, vol 131. Springer, Cham, pp 465-474. https://doi.org/10.1007/978-3-030-47415-7 49

[46] Binsahl H., Chang S., Bosua R. (2015). Identity and belonging: Saudi female international students and their use of social networking sites. Crossings J Migr Cult 6:81-102 . https://doi.org/10.1386/cjmc.6.1.81_1

[47] Chen L., Yang X. (2015). Nature and effectiveness of online social support for intercultural adaptation of Mainland Chinese international students. Int J Commun 9:2161-2181

[48] Lin J-H., Peng W., Kim M., Kim S.Y., LaRose R. (2012). Social networking and adjustments among international students. New Media Soc 14:421-440 . https://doi.org/ $10.1177 / 1461444811418627$

[49] Nseke P. (2018). How International Students Adapt in China: The Role of Chinese Social Media in Intercultural Adaptation. Int J Manag Sci Bus Adm 4:44-50 . https://doi.org/ 10.18775/ijmsba.1849-5664-5419.2014.45.1005

[50] Wang W., Huang T., Huang S., Wang L. (2009). Internet use, group identity, and political participation among Taiwanese Americans. China Media Res 5:4762

[51] Chandra A.Y., Prasetyaningrum P.T., Suria O., Santosa P.I., Nugroho L.E. (2021). Virtual Reality Mobile Application Development with Scrum Framework as a New Media in Learning English. Int J Interact Mob Technol 15:31 . https://doi.org/10.3991/ ijim.v15i08.19923

[52] Lee L. (2012). Engaging Study Abroad Students in Intercultural Learning Through Blogging and Ethnographic Interviews. Foreign Lang Ann 45:7-21 . https://doi.org/10.1111/j.19449720.2012.01164.x

[53] Melo-Pfeifer S. (2015). Blogs and the development of plurilingual and intercultural competence: report of a co-actional approach in Portuguese foreign language classroom. Comput Assist Lang Learn 28:220-240 . https://doi.org/10.1080/09588221.2013.818556

[54] Peter the Great St. Petersburg Polytechnic University Drone Flight (Chinese) (2021).. International Programs SPbPU, Russia. https://www.youtube.com/watch?v=ASMpO5 kOzeM

[55] Ivanova E., Polyakova M., Abakumova M. (2020). Implementing a Blended Learning Approach to Foreign Language Teaching at SPbPU. IOP Conf Ser Mater Sci Eng 940:012138 . https://doi.org/10.1088/1757-899x/940/1/012138

[56] Sinyakin I.I., Samorodova E.A. Belyaeva I.G. (2020). Linguistic analysis of the peculiarities of the French-language legal task texts. XLinguae 13:17-32 . https://doi.org/10.18355/xl. $\underline{2020.13 .02 .02}$ 
[57] Mary Frances L., Huguet-Jérez M., Bakieva M. (2018). Prior Experience and Student Satisfaction with E-Tandem Language Learning of Spanish and English. Int J Interact Mob Technol 12:4 . https://doi.org/10.3991/ijim.v12i4.9196

[58] Samorodova E.A,. Ogorodov M.K., Belyaeva I.G., Savelyeva E.B. (2020). The study of practical legal cases as an effective method of acquiring the discursive communicative skills of international jurists when learning the professional foreign language (professional French). XLinguae 13:121-138 . https://doi.org/10.18355/x1.2020.13.01.10

[59] Chua N.A., Soon G.Y. (2021). Performing Communicative Language Teaching in Mandarin Mobile Learning. Int J Interact Mob Technol 15:87 . https://doi.org/10.3991/ ijim.v15i05.20899

[60] de Hei M., Tabacaru C., Sjoer E, Rippe R., Walenkamp J. (2020). Developing Intercultural Competence Through Collaborative Learning in International Higher Education. J Stud Int Educ 24:190-211 . https://doi.org/10.1177/1028315319826226

[61] Almazova N., Eremin Y., Kats N., Rubtsova A. (2020). Integrative multifunctional model of bilingual teacher education. IOP Conf Ser Mater Sci Eng 940:012134 . https://doi.org/10.1088/1757-899X/940/1/012134

[62] Baranova T., Kobicheva A., Tokareva E. (2021). The Impact of an Online Intercultural Project on Students' Cultural Intelligence Development. In: D. Bylieva, A. Nordmann, O. Shipunova VV (ed) Knowledge in the Information Society. PCSF 2020, CSIS 2020. Lecture Notes in Networks and Systems, vol 184. Springer, Cham, pp 219-229. https://doi.org/10.1007/978-3-030-65857-1_19

[63] Medvedeva O.D., Andreeva S.S., Krepkaia T.N. (2020). Teaching listening comprehension through online academic lectures. IOP Conf Ser Mater Sci Eng 940:012139. https://doi.org/10.1088/1757-899X/940/1/012139

[64] Samorodova E.A., Belyaeva I.G., Bakaeva S.A. (2021). Analysis of communicative methods effectiveness in teaching foreign languages during the coronavirus epidemic: distance format. XLinguae 14:131-140 . https://doi.org/10.18355/XL.2021.14.01.11

[65] Schlabach, J., Hufeisen, B. (2021). Plurilingual School and University Curricula. Technol. Lang. 2, 126-141. https://doi.org/10.48417/technolang.2021.02.12

[66] Spencer-Oatey H., Xiong Z. (2006). Chinese Students' Psychological and Sociocultural Adjustments to Britain: An Empirical Study. Lang Cult Curric 19:37-53 . https://doi.org/10.1080/07908310608668753

[67] Park E., Klieve H., Tsurutani C., Harte W. (2017). International students' accented English-Communication difficulties and developed strategies. Cogent Educ 4: . https://doi.org/10.1080/2331186X.2017.1314651

[68] Astarita C., Patience A. (2020). Chinese students' access to media information in Australia and France: a comparative perspective. Media Int Aust 175:65-78 . https://doi.org/10. $\underline{1177 / 1329878 X 20905695}$

[69] Chang S., Gomes C. (2017). Digital journeys: A perspective on understanding the digital experiences of international students. J Int Students 7:347-366 . https://doi.org/10.32674/jis. v7i2.385

[70] Hodis G.M., Hodis F.A. (2012). A Mediation Analysis of International Students' Patterns of Computer-Mediated Communication. Int J Commun 6:2846-2869

[71] Liu Y. (2020). Rebellion of the Chinese Language in Technological Age. Technol Lang 1:57-60 . https://doi.org/10.48417/technolang.2020.01.13 


\section{Authors}

Daria Bylieva is an associate professor at the Social Science Department of Peter the Great St. Petersburg Polytechnic University, Polytechnicheskaya 29, Saint Petersburg, 195251, Russia. She is the editor of the interdisciplinary international journal Technology and Language. Dr. Bylieva is the author of over 150 articles about contemporary problems of education and communication, as well as coeditor some collection of the articles on those topics.

Victor Krasnoshchekov is director of Higher School of International Educational Programs of Peter the Great St. Petersburg Polytechnic University, Polytechnicheskaya 29, Saint Petersburg, 195251, Russia, and a laureate of the St. Petersburg Government Prize in the field of education and science. His research interests include international education and modern educational technologies. (Email: krasno_vv@spbstu.ru).

Victoria Lobatyuk is an associate professor at the Social Science Department of Peter the Great St. Petersburg Polytechnic University, Russia. She has published over 100 scientific articles about the problems of society and higher education (Email: lobatyuk_vv@spbstu.ru).

Anna Rubtsova is director of the Graduate School of Applied Linguistic, Interpreting and Translation, Peter the Great St. Petersburg Polytechnic University, Polytechnicheskaya 29, St Petersburg, 195251, Russia. She is an Editorial Board member of several peer-reviewed journals. Her research interests mainly focus on applied linguistics, language learning, and intercultural communication (Email: rubtsova_av@spb stu.ru).

Li Wang is director of Russian Language Teaching and Research Center at Jiangsu Normal University, Shanghai Road, Tongshan District, Xuzhou, Jiangsu Province P.R.China 221116. She conducts research in the field of teaching methods of Russian as a foreign language and e-learning (Email: wanglidr@163.com).

Article submitted 2021-07-03. Resubmitted 2021-08-12. Final acceptance 2021-08-13. Final version published as submitted by the authors. 